\title{
Prevalensi cendawan entomopatogenik, Neozygites fumosa (Speare) Remaudie're \& Keller (Zygomycetes: Entomophthorales) pada populasi kutu putih, Paracoccus marginatus Williams \& Granara De Willink (Hemiptera: Pseudococcidae) di wilayah Bogor
}

\author{
Prevalence of entomopathogenic fungus, Neozygites fumosa (Speare) \\ Remaudie're \& Keller (Zygomycetes: Entomophthorales) on \\ population of Paracoccus marginatus Williams \& Granara \\ De Willink (Hemiptera: Pseudococcidae) in Bogor area
}

\author{
Anik Nurhayati, Ruly Anwar* \\ Departemen Proteksi Tanaman, Fakultas Pertanian, Institut Pertanian Bogor \\ Jalan Kamper, Kampus IPB Dramaga 16680
}

(diterima Mei 2012, disetujui Agustus 2012)

\begin{abstract}
ABSTRAK
Prevalensi cendawan entomopatogenik, Neozygites fumosa (Zygomycetes: Entomophthorales) pada kutu putih pepaya, Paracoccus marginatus (Hemiptera: Pseudococcidae) telah diteliti pada tanaman pepaya dan ubi kayu di Bogor tahun 2011. Tiga puluh tanaman pepaya dan tiga puluh tanaman ubi kayu diambil sebagai tanaman contoh pada masing-masing lahan pengamatan, di Desa Pasir Gaok, Kecamatan Rancabungur dan Kelurahan Bubulak, Kecamatan Bogor Barat Pengamatan dilakukan sebanyak 8 kali dengan rentang waktu seminggu sekali untuk penghitungan jumlah populasi kutu putih dan seminggu dua kali untuk pengambilan kutu putih yang terinfeksi cendawan. Hasil pengamatan menunjukkan bahwa kutu putih ubi kayu, Phenacoccus manihoti tidak ditemukan pada kedua tanaman di dua lokasi pengamatan. Spesies kutu putih yang ditemukan pada pepaya dan ubikayu adalah kutu putih pepaya, $P$. marginatus. Populasi kutu tersebut di Wilayah Bogor Barat secara nyata lebih tinggi dibandingkan populasi kutu putih di Rancabungur. Populasi $P$. marginatus pada tanaman pepaya lebih tinggi dibandingkan jumlah $P$. marginatus pada tanaman ubi kayu. Meskipun demikian, tingkat infeksi $N$. fumosa pada kutu putih tersebut tidak menunjukkan perbedaan yang nyata pada kedua jenis tanaman maupun pada kedua lokasi pengamatan.
\end{abstract}

Kata kunci: Paracoccus marginatus, Neozygites, pepaya, ubi kayu, prevalensi

\begin{abstract}
The prevalence of entomopathogenic fungus, Neozygites fumosa (Zygomycetes: Entomophthorales) on the papaya mealybug, Paracoccus marginatus (Hemiptera: Pseudococcidae), was studied in Bogor in two districts: Bubulak and Rancabungur in 2011. Thirty plants of either papaya or cassavas were sampled 8 times, once a week for insect population and biweekly for the fungus infection sampling. The results showed that the cassava mealybug was not found on both plants and all locations. The populations of papaya mealybug in Bubulak were higher than in Rancabungur. The populations of papaya mealybug on papaya were higher than those of cassava. However, $N$. fumosa infection levels on both plants and both locations were not significantly different.
\end{abstract}

Key words: Paracoccus marginatus, Neozygites, papaya, cassava, prevalence

\footnotetext{
*Penulis korespondensi: Ruly Anwar. Departemen Proteksi Tanaman, Fakultas Pertanian, Institut Pertanian Bogor,

Jalan Kamper, Kampus IPB, Dramaga 16680

Tel: 0251-8629364, Faks: 0251 8629364, Email: rakosasih@gmail.com
} 


\section{PENDAHULUAN}

Invansi hama asing seringkali terjadi di Indonesia. Salah satu contoh terakhir adalah masuknya Paracoccus marginatus William \& Granara de Willink (Hemiptera: Pseudococcidae) yang terjadi pada pertengahan tahun 2008 (Muniappan et al. 2008). Ribuan pohon pepaya di Kecamatan Sukaraja, Kabupaten Bogor diserang oleh serangga hama ini. Penelitian Sartiami et al. (2009) melaporkan bahwa kutu putih pepaya telah terdeteksi di Kabupaten dan Kota Bogor, Sukabumi, Cianjur, Tanggerang dan DKI Jakarta. Serangan hama ini mengakibatkan petani pepaya di beberapa daerah mengalami kerugian ekonomi. Sartiami et al. (2009) juga menyebutkan bahwa $P$. marginatus merupakan serangga hama polifag dan dapat menyerang 21 jenis tumbuhan. Serangan hama ini dapat menurunkan produksi hingga $85 \%$ dan kerugian ekonomi sampai $88 \%$, karena tanaman mati sebelum dipanen (Ivakdalam 2010). Serangan kutu putih pepaya di Indonesia menjadi kompleks karena tidak adanya musuh alami yang efektif yang dapat menekan serangan hama tersebut. Di negara asalnya, serangan hama ini dapat dikendalikan menggunakan musuh alami yaitu parasitoid dan predator (Amarasekare et al. 2008). Begitu pula halnya dengan keberadaan kutu putih ubi kayu (P. manihoti) yang menyebabkan kerusakan pertanaman ubi kayu di negara Afrika dan Amerika Selatan (Calatayud \& Le Rü 2006).

Adanya invansi hama baru kutu putih ini ke wilayah Indonesia mengharuskan Indonesia melakukan pengendalian terhadap hama tersebut. Cara pengendalian yang dilakukan haruslah tepat dan tidak berbahaya bagi lingkungan. Oleh karena itu, perlu dicarikan cara pengendalian yang ramah lingkungan seperti pengendalian secara biologi dengan memanfaatkan organisme ataupun mikroorganisme antagonis. Saat ini sudah banyak peneliti yang melaporkan keberhasilan melakukan pengandalian secara biologi, yaitu baik dengan menggunakan musuh alami berupa parasitoid, predator maupun mikroorganisme seperti virus atau cendawan (Hajek 2004)

Beberapa penelitian menunjukan bahwa cendawan Entomophthorales mampu mengendalikan populasi serangga hama dan tungau. Ordo ini merupakan jenis cendawan obligat yang berpotensi sebagai musuh alami beberapa serangga hama karena cendawan ini memiliki kemampuan epizootic (Hajek 2004). Keller dan Wegensteiner (2007) melaporkan bahwa cendawan ordo Entomophthorales memiliki 5 famili, yaitu Ancylistaceae, Completoriaceae, Entomophthoraceae, Meristacraceae dan Neozygitaceae. Semua famili di atas, kecuali Completoriaceae mempunyai anggota yang bersifat entomopatogenik. Hasil identifikasi menunjukkan bahwa 176 spesiesnya menyerang serangga. Sembilan spesies diketahui bersifat patogenik pada Arachnida, 7 spesies ditemukan pada Acari dan 2 spesies pada Phalangiidae. Sebagian besar spesies (34\% atau sekitar 68 spesies) ditemukan pada Diptera, 23\% pada Homoptera, dan kurang dari 10\% ditemukan pada inang lainnya, seperti spesies yang menyerang Trichoptera, Collembola, Dictyoptera (Blattaria) dan Rhaphidoptera.

Cendawan Entomophthorales yang menjadi cendawan patogenik pada arthropoda diketahui berasal dari famili Ancylistaceae (genus Conidiobolus), Entomophthoracae (12 genera) dan Neozygitaceae (2 genera). Famili Meristacraceae hanya dari spesies Meritacrum mikoi yang merupakan patogen larva Tabanidae (Diptera) (Keller 2007).

Jumlah total cendawan Entomophthorales yang telah teridentifikasi adalah sebanyak 16 genus dan 233 spesies. Sebagian besar cendawan entomopatogenik termasuk ke dalam famili Entomophthoraceae 195 spesies $(87,4 \%), 17$ spesies termasuk ke dalam famili Neozygitaceae dan 10 spesies Ancylistaceae yang masingmasing memiliki persentasi sebesar $7,6 \%$ dan $4,4 \%$, sedangkan anggota dari famili Meristacraceae hanya memiliki satu jenis spesies cendawan entomopatogenik. Spesies dari famili Neozygitaceae umumnya menyerang serangga dari ordo Thysanophtera dan sebagian Hemipetra (kutu-kutuan), sedangkan spesies dari famili Entomophthoraceae umumnya menyerang sebagian Hemiptera (termasuk jenis wereng) dan beberapa serangga dari ordo Diptera, Lepidoptera dan Coleoptera (Keller 2007).

Delalibera et al. (1997) menyebutkan bahwa Neozygites fumosa (Speare) Remaudie're \& Keller (Zygomycetes: Entomophthorales) merupakan patogen dari Phenacoccus herreni Cox \& Williams 
(Hemiptera: Pseudococcidae) di Brazil. Tingkat infeksi cendawan tersebut mencapai $64,6 \%$. Selain itu, cendawan tersebut juga dilaporkan menginfeksi kutu putih Planococcus citri pada tanaman jeruk di Florida dan efektif sebagai musuh alami bagi kutu putih $P$. manihoti pada tanaman ubi kayu di Kongo. Hal yang sama juga dilaporkan oleh Shylena (2010) bahwa kutu putih pepaya di Wilayah Sukaraja dan Rancabungur telah terinfeksi cendawan Entomophthorales. Oleh karena itu, penelitian ini bertujuan untuk mengetahui potensi cendawan Entomopatogen, $N$. fumosa pada kutu putih pepaya, P. marginatus pada pepaya dan ubi kayu di Wilayah Bogor.

\section{BAHAN DAN METODE}

\section{Kecamatan Rancabungur, Desa Pasir Gaok}

Kecamatan Rancabungur merupakan salah satu wilayah administratif di Kabupaten Bogor yang berada di ketinggian 243 meter di atas permukaan laut (dpl.). Desa tersebut merupakan daerah sentra pertanian di Kecamatan Rancabungur. Mayoritas lahan pertanian adalah lahan sawah sisanya merupakan tegalan. Komoditas pertanian yang banyak ditanam petani adalah padi, jagung, ubi kayu, ubi jalar, cabai dan pepaya.

Lahan pepaya yang digunakan dalam penelitian ini memiliki luas $1800 \mathrm{~m}^{2}$ dengan populasi 350 tanaman yang ditanam dengan jarak 2,5 m x 1,5 m. Varietas pepaya yang ditanam adalah California dan Bangkok. Lahan pepaya di Rancabungur berdekatan dengan lahan pertanaman ubi kayu dan lahan pertanaman jagung yang ditanam tumpang sari dengan tanaman ubi jalar.

Tanaman ubi kayu di Rancabungur yang digunakan sebagai lahan penelitian ditanam pada lahan seluas $1400 \mathrm{~m}^{2}$ dengan jarak tanam $50 \mathrm{~cm}$ x $50 \mathrm{~cm}$ serta populasi sebanyak 600 tanaman. Tanaman ubi kayu ditanam secara monokultur. Lokasi lahan pertanaman ubi kayu berdekatan dengan lahan pepaya.

\section{Kecamatan Bogor Barat, Kelurahan Bubulak}

Kelurahan Bubulak, Kecamatan Bogor Barat berada di wilayah administratif Kota Bogor yang berada di ketinggian tempat $207 \mathrm{~m}$ dpl. Sebagian besar wilayah Kelurahan Bubulak terdiri atas daerah permukiman dan perkantoran. Namun demikian, di wilayah tersebut masih dijumpai lahan pertanian yang banyak ditanami komoditas palawija dan sayuran. Komoditas lainnya adalah talas, ubi kayu, ubi jalar, pepaya, jagung, terong dan lidah buaya.

Lahan pepaya yang digunakan dalam penelitian ini memiliki luas $1400 \mathrm{~m}^{2}$ dengan populasi 180 tanaman yang berjarak tanam $2 \mathrm{~m}$ x $1 \mathrm{~m}$. Pepaya yang ditanam merupakan varietas California dan varietas Bangkok. Tanaman pepaya ditanam secara tumpang sari dengan tanaman talas.

Lokasi pertanaman ubi kayu yang diamati adalah lahan dengan luas $1600 \mathrm{~m}^{2}$ dengan jarak tanam $50 \mathrm{~cm} \times 50 \mathrm{~cm}$ serta populasi sebanyak 1000 tanaman. Tanaman ubi kayu ditanam secara monokultur yang berdekatan dengan lahan pertanaman jagung.

\section{Penentuan tanaman sampel}

Tiga puluh tanaman pepaya dan ubi kayu dipilih secara sistematis dengan pola diagonal. Tanaman yang telah dipilih kemudian ditandai dengan tali agar mempermudah pengamatan berikutnya.

\section{Pengambilan sampel dan pengamatan populasi P. marginatus}

Pengambilan sampel kutu putih untuk menentukan infeksi cendawan terhadap kutu putih dilakukan seminggu 2 kali selama 4 minggu. Pengambilan, dimulai pada tanggal 8 Maret 2011 dan berakhir pada 1 April 2011. Sampel kutu putih yang sudah diambil dari lapangan dimasukkan ke dalam botol yang berisi larutan alkohol $70 \%$ untuk dilakukan pengujian lebih lanjut di laboratorium.

Pengamatan populasi kutu putih dilakukan seminggu sekali selama enam minggu. Pengamatan populasi kutu putih dilakukan dengan menghitung jumlah kutu putih $P$. marginatus yang ada pada daun (pepaya dan ubi kayu) tanaman contoh. Pengamatan populasi kutu putih dan luas serangan dilakukan mulai tanggal 16 Maret 2011 sampai 20 April 2011.

\section{Koleksi dan preparasi preparat cendawan yang menginfeksi $P$. marginatus}

Kutu putih yang telah diambil dari lapangan kemudian dibuat preparat. Pembuatan preparat dilakukan dengan menggunakan pewarna 
lactophenol-cotton blue. Sepuluh ekor kutu putih diletakkan pada gelas objek dan disusun secara diagonal, kemudian ditutup dengan gelas penutup. Preparat-preparat yang telah dibuat kemudian diamati dengan menggunakan mikroskop compound.

\section{Identifikasi stadia cendawan Entomophthorales}

Preparat kutu putih yang telah dibuat diamati dan diidentifikasi stadia cendawan Entomophthorales yang menginfeksi serangga tersebut. Kutu putih pepaya yang terinfeksi cendawan Entomophthorales digolongkan ke dalam salah satu diantara 6 kategori (Steinkraus et al. 1995), yaitu (1) sehat, (2) terinfeksi secondary conidia (konidia sekunder), (3) terinfeksi hyphal bodies, (4) terinfeksi primary conidia dan konidiofor, (5) terserang resting spores, dan (6) terinfeksi cendawan saprofit. Identifikasi cendawan Entomophthorales dilakukan dengan melihat bentuk dan ukuran konidiofor, konidia primer, dan konidia sekunder (ragam bentuknya). Proses identifikasi lebih lanjut dan lebih jelas dilakukan dengan melihat struktur hyphal bodies, cystidia, rizoid, resting spores dan jumlah inti sel masing-masing struktur (Keller 2007).

\section{Perhitungan tingkat infeksi cendawan Entomo- phthorales}

Tingkat infeksi cendawan Entomopthorales pada P. marginatus di lapangan dihitung dengan menggunakan rumus :

Tingkat infeksi $\%=\frac{\sum \text { kutu putih terinfeksi }}{\sum \begin{array}{c}\sum \text { populasi sampel } \\ \text { kutu putih }\end{array}} \times 100 \%$

\section{Rancangan percobaan}

Penelitian ini dilakukan dengan metode penarikan contoh keadaan kelimpahan populasi kutu putih papaya dan kutu putih ubik kayu serta tingkat infeksi $N$. fumosa pada kutu putih tersebut di lapangan. Penarikan contoh dilakukan untuk membandingkan kedua peubah tersebut antara kedua tanaman (papaya dan ubi kayu) dan dua lokasi. (Rancabungur dan Bubulak). Pada masingmasing lokasi terdiri dari 30 tanaman papaya dan 30 tanaman ubikayu dijadikan tanaman contoh. (Rancabungur dan Bubulak).

\section{Analisis data}

Data kelimpahan populasi $P$. marginatus dan tingkat infeksi $N$. fumosa terhadap $P$. marginatus dianalisis dengan uji t-student $(\alpha=0,05)$ menggunakan program Minitab 16.

\section{HASIL}

\section{Populasi kutu putih}

Kutu putih yang ditemukan baik pada tanaman pepaya maupun ubikayu di dua lokasi pengamatan adalah kutu putih pepaya, P. marginatus. Spesies kutu putih ubikayu, $P$. manihoti, tidak ditemukan selama pengamatan. Secara umum kelimpahan populasi $P$. marginatus di dua lokasi setiap minggunya mengalami peningkatan, kecuali pada minggu ketiga dan kelima. Hal ini terjadi karena pada pengamatan minggu ketiga dan kelima terjadi hujan yang cukup lebat. Pada sehari sebelum pengamatan juga terjadi hujan ringan. Hal ini menyebabkan berkurangnya populasi $P$. marginatus pada tanaman. Hasil pengamatan ini juga diperkuat dengan data dari BMKG Stasiun Klimatologi Darmaga Bogor (2011) yang menyatakan bahwa curah hujan pada bulan Maret dan April adalah 140,0 mm dan 278, $4 \mathrm{~mm}$.

Terdapat perbedaan kelimpahan populasi $P$. marginatus di dua lokasi pengamatan (Tabel 1). Populasi kutu putih di Bubulak secara umum lebih tinggi dibandingkan dengan di Rancabungur, terutama pada pengamatan ke-1 dan ke-3. Hal ini terjadi karena lahan pertanian di Bubulak kurang terawat. Petani di lokasi tersebut tidak melakukan pembersihan gulma dan tindakan pengendalian lain terhadap organisme pengganggu tanaman (OPT) yang ada di pertanaman pepaya maupun ubi kayu.

Kelimpahan populasi $P$. marginatus pada tanaman pepaya lebih tinggi dibandingkan dengan pada tanaman ubi kayu pada semua waktu pengamatan, kecuali pengamatan ke-5 (Tabel 2). Hal ini terjadi karena tanaman pepaya merupakan inang utama $P$. marginatus, sedangkan tanaman ubi kayu merupakan inang alternatif.

\section{Cendawan Entomophthorales yang menginfeksi P. marginatus}

Preparat kutu putih yang berhasil dikumpulkan berjumlah 503 preparat, 253 diantaranya preparat 
kutu putih yang dikumpulkan dari lokasi Bubulak, dan 250 sisanya merupakan preparat kutu putih yang berasal dari Rancabungur. Berdasarkan hasil identifikasi stadia cendawan yang ditemukan pada kutu putih yang dikoleksi di dua lokasi adalah stadia secondary conidia, prymary conidia, hyphal bodies, dan cendawan saprofit.

Stadia resting spores tidak ditemukan pada sampel yang diambil dari dua lokasi pengamatan tersebut. Hal ini dikarenakan stadia resting spores merupakan struktur bertahan yang dimiliki cendawan Entomophthorales saat tidak ada inang atau saat tidak aktif.

Tubuh kutu putih yang sehat (Gambar 1a) akan mulai terinfeksi oleh cendawan jika bagian tubuhnya, seperti bagian tungkai, antena, dan bagian tubuh lainnya ditemukan konidia sekunder (Gambar 1b). Konidia tersebut ini bersifat infektif dan mampu berkecambah dan menembus tubuh seranga. Cendawan akan terus berkembang dalam tubuh inang dan membentuk hyphal bodies (Gambar 1e). Struktur ini akan memenuhi seluruh tubuh bagian dalam inang sampai inang itu mati.

Tabel 1. Kelimpahan populasi Paracoccus marginatus di Rancabungur dan Bubulak

\begin{tabular}{|c|c|c|c|}
\hline \multirow{2}{*}{$\begin{array}{l}\text { Pengamatan } \\
\text { minggu ke-* } \\
\pm \text { sd }\end{array}$} & \multicolumn{2}{|c|}{ Lokasi } & \multirow{2}{*}{ Nilai $p$} \\
\hline & Rancabungur & Bubulak & \\
\hline 1 & $10,4 \pm 11,7 \mathrm{a}$ & $22,7 \pm 29,4 b$ & 0,0034 \\
\hline 2 & $28,1 \pm 22,0 \mathrm{a}$ & $26,9 \pm 25,5 \mathrm{a}$ & 0,77 \\
\hline 3 & $16,4 \pm 10,2 \mathrm{a}$ & $23,4 \pm 18,3 b$ & 0,012 \\
\hline 4 & $29,1 \pm 23,8 \mathrm{a}$ & $29,4 \pm 16,5 \mathrm{a}$ & 0,94 \\
\hline 5 & $24,2 \pm 21,6 \mathrm{a}$ & $30,8 \pm 22,0 \mathrm{a}$ & 0,096 \\
\hline 6 & $27,4 \pm 21,1 \mathrm{a}$ & $29,8 \pm 17,3 \mathrm{a}$ & 0,50 \\
\hline
\end{tabular}

Tabel 2. Kelimpahan populasi Paracoccus marginatus pada tanaman pepaya dan ubi kayu

\begin{tabular}{llcl}
\hline $\begin{array}{l}\text { Pengamatan } \\
\text { minggu ke-* } \\
\pm \text { sd }\end{array}$ & \multicolumn{2}{c}{ Tanaman } & Nilai $\mathrm{p}$ \\
\cline { 2 - 3 } & Pepaya & Ubi kayu & \\
\hline 1 & $24,4 \pm 28.3 \mathrm{a}$ & $8,6 \pm 12.1 \mathrm{~b}$ & 0,0002 \\
2 & $38,1 \pm 25,4 \mathrm{a}$ & $16,9 \pm 16,2 \mathrm{~b}$ & 0,0000 \\
3 & $28,40 \pm 16,2 \mathrm{a}$ & $11,33 \pm 7,36 \mathrm{~b}$ & 0,0000 \\
4 & $37,9 \pm 19,6 \mathrm{a}$ & $20,6 \pm 17,4 \mathrm{~b}$ & 0,0000 \\
5 & $30,2 \pm 18,1 \mathrm{a}$ & $24,8 \pm 25,1 \mathrm{a}$ & 0,18 \\
6 & $36,0 \pm 19,6 \mathrm{a}$ & $21,1 \pm 15,9 \mathrm{~b}$ & 0,0000 \\
\hline
\end{tabular}

*Angka selajur yang diikuti huruf yang sama tidak berbeda nyata pada taraf nyata pada uji t-student $(\alpha=0,05)$
Konidiofor akan terbentuk dan akan menembus ke luar tubuh inang dan menyebabkan tubuh kutu putih menjadi rusak (Gambar 1d). Konidia primer (Gambar 1c dan 1d) akan terbentuk di ujung konidiofor. Pada kondisi yang optimum, terutama kelembaban lingkungan yang mendekati jenuh, konidia primer akan dilepaskan ke lingkungan sekitar kadaver kutu putih. Proses pelepasan konidia primer dari konidiofor dinamakan sporulasi. Konidia primer ini sangat labil dan tidak infektif. Dengan demikian, pada konidia primer akan terbentuk struktur kapiler yang pada bagian ujungnya akan membentuk konidia sekunder atau kapilikonidia. Konidia sekunder yang ditemukan menempel pada bagian antena serangga (Gambar 1b). Kutu putih yang mati dan ditinggalkan oleh cendawan Entomophthorales tersebut akan membusuk dan mengundang cendawan saprofitik (Gambar 1f) dan menginfeksi serangga saat proses infeksi dari cendawan Entomophthorales sudah selesai dan serangga yang terinfeksi mati. Cendawan saprofit akan dapat menginfeksi hanya pada serangga-seranga yang mati karena infeksi cendawan primer (obligat) seperti cendawan Entomophthorales yang menjadi penyebab penyakit primer kutu putih tersebut. Di lapangan, keberadaan cendawan saprofitik tersebut seringkali menjadi salah satu penyebab kesalahan identifikasi patogen penyebab penyakit.

Konidia primer yang ditemukan pada sampel kutu putih berbentuk mirip buah pir (Gambar 2a dan 2 b). Konidia primer selalu ditemukan kapiler (Gambar 2b) yang akan membentuk konidia sekunder atau capiliconidia yang berbentuk bulat telur dengan ujungnya yang meruncing (memiliki papil) (Gambar 2c). Hyphal bodies yang ditemukan berbentuk bulat kecil dan banyak memenuhi seluruh rongga dalam tubuh inang (Gambar 2d). Berdasarkan ciri-ciri yang disebutkan di atas, cendawan Entomophthorales yang menginfeksi P. marginatus tersebut dipastikan termasuk dalam genus Neozygites.

\section{Tingkat infeksi cendawan Entomophthorales}

Tingkat infeksi cendawan Entomophthorales pada $P$. marginatus di Kecamatan Rancabungur tidak berbeda nyata dengan di Bubulak (Tabel 3). Hasil yang sama juga terjadi pada tingkat infeksi cendawan Entomophthorales terhadap 


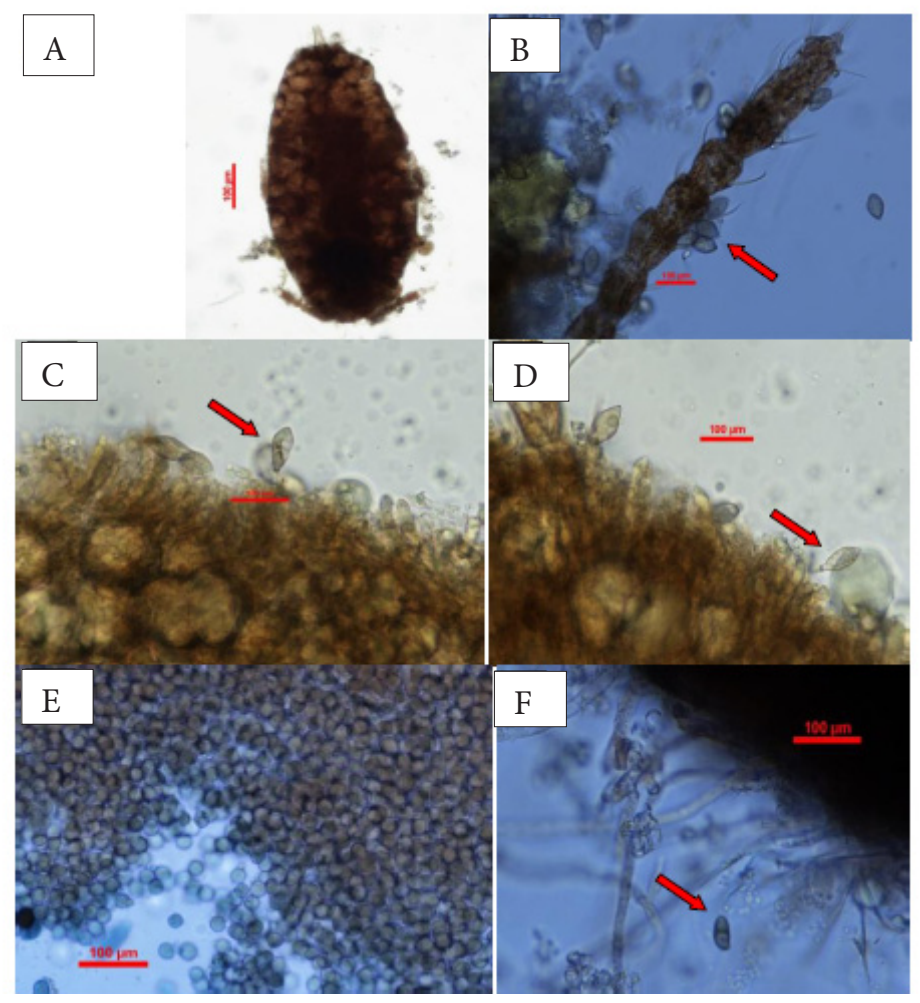

Gambar 1. Stadia cendawan Entomophthorales yang ditemukan saat pengamatan. A: kutu putih sehat; B: konidia sekunder yang menempel pada antena kutu putih; C dan D, konidia primer yang terbentuk di tubuh kutu putih; E: hyphal bodies yang berbentuk bulat kecil; F: cendawan saprofitik menginfeksi kutu putih yang sudah mati.

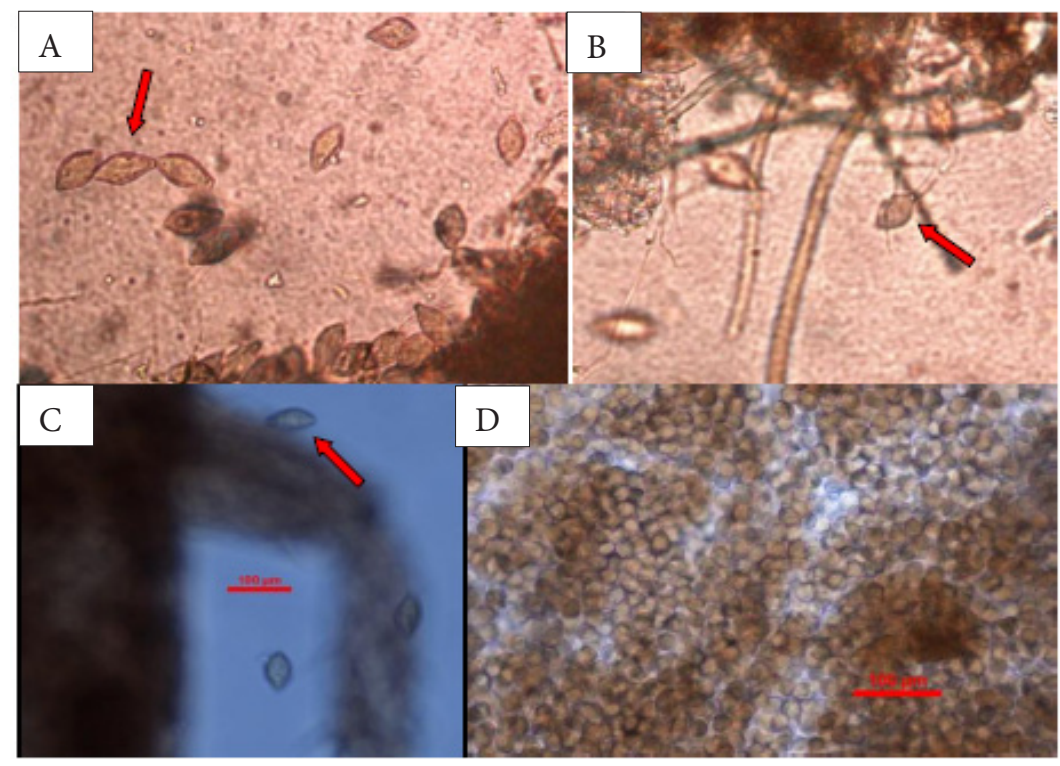

Gambar 2. Cendawan Entomophthorales yang menginfeksi kutu putih. A dan B: kutu putih yang terinfeksi konidia primer; C: konidia sekunder yang menempel pada bagian tubuh kutu putih; D: hyphal bodies yang terbentuk di dalam tubuh kutu putih (hampir mengisi seluruh bagian tubuh).

P. marginatus pada tanaman pepaya dan ubi kayu (Tabel 4).

Kelimpahan populasi kutu yang tinggi biasanya menyebabkan tingkat infeksi yang lebih tinggi. Hal ini terjadi pada populasi kutu putih di Bubulak yang mempunyai kelimpahan lebih tinggi dibandingkan populasi di Rancabungur. Perbedaan tingkat infeksi yang terjadi hanya 
Tabel 3. Persentase tingkat infeksi cendawan Entomophthorales pada Pacoccus marginatus di wilayah Rancabungur dan Bubulak

\begin{tabular}{llll}
\hline $\begin{array}{l}\text { Tingkat infeksi } \\
\text { cendawan } \\
\text { pengamatan } \\
\begin{array}{l}\text { minggu ke- } \\
\pm \text { sd }\end{array}\end{array}$ & Rancabungur & Bubulak & \\
\cline { 2 - 3 } & & & Nilai p \\
\hline 1 & $13,9 \pm 13,2 \mathrm{a}$ & $17,8 \pm 12,6 \mathrm{a}$ & 0,61 \\
2 & $12,8 \pm 10,2 \mathrm{a}$ & $23,9 \pm 12,6 \mathrm{a}$ & 0,13 \\
3 & $41,5 \pm 13,0 \mathrm{a}$ & $40,3 \pm 17,6 \mathrm{a}$ & 0,89 \\
4 & $13,0 \pm 15,0 \mathrm{a}$ & $30,3 \pm 15,9 \mathrm{a}$ & 0,083 \\
5 & $15,33 \pm 9,77 \mathrm{a}$ & $25,70 \pm 18,10$ a & 0,26 \\
6 & $17,58 \pm 9,83 \mathrm{a}$ & $0,00 \pm 23,0 \mathrm{a}$ & 0,27 \\
7 & $5,40 \pm 7,03 \mathrm{a}$ & $28,3 \pm 23,1 \mathrm{a}$ & 0,67 \\
8 & $11,3 \pm 12,2 \mathrm{a}$ & $33,7 \pm 33,1 \mathrm{a}$ & 0,17 \\
\hline
\end{tabular}

*Angka selajur yang diikuti huruf yang sama tidak berbeda nyata pada taraf nyata pada uji t-student $(\alpha=0,05)$

Tabel 4. Persentase tingkat infeksi cendawan Entomopthorales terhadap Paracoccus marginatus pada tanaman pepaya dan ubi kayu

\begin{tabular}{|c|c|c|c|}
\hline \multirow{2}{*}{$\begin{array}{l}\text { Tingkat infeksi } \\
\text { cendawan } \\
\text { pengamatan } \\
\text { minggu ke- * } \\
\pm \text { sd }\end{array}$} & \multicolumn{2}{|c|}{ Tanaman } & \multirow{2}{*}{ Nilai $p$} \\
\hline & Pepaya & Ubi kayu & \\
\hline 1 & $14,0 \pm 15,3 \mathrm{a}$ & $17,7 \pm 10,0 \mathrm{a}$ & 0,64 \\
\hline 2 & $18,3 \pm 15,4 \mathrm{a}$ & $18,3 \pm 10,0 \mathrm{a}$ & 1,0 \\
\hline 3 & $46,3 \pm 15,6 \mathrm{a}$ & $35,4 \pm 12,8 \mathrm{a}$ & 0,22 \\
\hline 4 & $23,7 \pm 21,8 \mathrm{a}$ & $19,7 \pm 13,0 \mathrm{a}$ & 0,71 \\
\hline 5 & $27,0 \pm 18,4 \mathrm{a}$ & $14,0 \pm 6,81 \mathrm{a}$ & 0,16 \\
\hline 6 & $28,60 \pm 25,10 \mathrm{a}$ & $19,00 \pm 5,76 \mathrm{a}$ & 0,40 \\
\hline 7 & $22,70 \pm 27,40 \mathrm{a}$ & $11,00 \pm 8,070 \mathrm{a}$ & 0,36 \\
\hline 8 & $30,10 \pm 36,70 \mathrm{a}$ & $15,00 \pm 7,77 \mathrm{a}$ & 0,37 \\
\hline
\end{tabular}

pada tanaman ubi kayu belum diketahui faktor penyebabnya. Tingkat infeksi cendawan Entomophthorales tertinggi mencapai 46,3\% yang terjadi pada kutu putih di tanaman pepaya di Bubulak, sedangkan tingkat infeksi terendah terjadi pada pengamatan ketujuh yaitu sebesar $5,4 \%$ pada kutu putih di pertanaman ubi kayu di Rancabungur.

Cendawan saprofit dapat menginfeksi kutuputih yang telah mati akibat infeksi cendawan Entomphthorales. Cendawan saprofit akan berkembang pada tubuh serangga yag sudah mati dan mendapat sumber makanan dari serangga yang sudah mati tersebut.

\section{PEMBAHASAN}

Kutu putih pepaya, P. marginatus dan kutuputih ubi kayu, $P$. manihoti merupakan dua spesies kutu putih yang bersifat invasif dari luar. $P$. manihoti tidak ditemukan pada waktu pengambilan contoh di lapangan, baik pada ubikayu maupun pepaya. Tahun 2010, kutu putih tersebut ditemukan pertama kali pada tanaman ubikayu di sekitar Kampus IPB (Rauf, komunikasi pribadi). Beberapa di antara kutu putih tersebut positif terinfeksi cendawan Entomophthorales. Infeksi $N$. fumosa pada kutu putih telah dilaporkan oleh Delalibera et al. (1997), namun pada Phenacoccus herreni, bukan pada kutu putih pepaya, $P$. marginatus. Meskipun demikian, kutu putih pepaya lebih dahulu ditemukan di Indonesia dibandingkan kutu putih ubikayu. Demikian juga cendawan Entomophthorales ditemukan pertama kali pada P. marginatus yang berbeda dengan yang pertama kali dilaporkan oleh Delalibera et al. (1997).

Populasi P. marginatus pada tanaman pepaya lebih tinggi dibandingkan populasi kutu putih tersebut pada ubikayu. Hasil penelitian ini sejalan dengan hasil yang dilaporkan oleh Maharani (2011) bahwa tanaman pepaya lebih mendukung laju intrinsik $P$. marginatus dibandingkan ubikayu. Keperidian $P$. marginatus yang hidup pada tanaman pepaya lebih tinggi dibandingkan dengan P. marginatus yang hidup pada tanaman ubi kayu. Namun demikian, infeksi cendawan $N$. fumosa pada kutu putih pepaya tidak menunjukkan perbedaan yang nyata pada kedua tanaman tersebut. Perbedaan kandungan senyawa kimia pada tanaman diduga dapat mempengaruhi perilaku makan serangga dan perilaku kopulasi serta tingkat reproduksinya. Kelimpahan populasi serangga pada tanaman dapat dipengaruhi oleh beberapa faktor fisik seperti curah hujan dan hembusan angin. Serangga kecil seperti kutukutuan (Hemiptera) dapat rentan terhadap tetesan air hujan dan hembusan angin. Tetesan hujan dan hembusan angin dapat menyebabkan serangga jatuh ke tanah dan tidak dapat kembali ke permukaan daun, sehingga kelimpahan populasi kutu pada daun akan berkurang (Steyenoff 2001).

Semakin tinggi kelimpahan populasi kutuputih menyebabkan tingkat infeksi cendawan terhadap serangga tersebut semakin tinggi. Namun 
demikian, hasil penelitian menunjukkan bahwa populasi kutu putih yang lebih tinggi di Bubulak dibandingkan populasi di Rancabungur tidak diiukuti oleh tingginya tingkat infeksi. Perbedaan tingkat infeksi terjadi hanya pada tanaman ubi kayu dan faktor penyebabnya belum diketahui. Tingkat infeksi cendawan Entomophthorales tertinggi mencapai $46,3 \%$ yang terjadi pada kutuputih di tanaman pepaya di Bubulak, sedangkan tingkat infeksi terendah terjadi pada pengamatn ketujuh yaitu sebesar 5,4\% pada kutu putih di pertanaman ubi kayu di Rancabungur. Hal yang serupa juga diungkapkan oleh Shylena (2010) bahwa tingkat infeksi cendawan Entomophthorales pada $P$. marginatus di wilayah Rancabungur dapat mencapai $65,94 \%$.

Cendawan Entomophthorales merupakan patogen obligat yang menginfeksi inang secara spesifik dan memiliki banyak stadia cendawan. Siklus hidup dari cendawan Entomophthorales cukup kompleks, biasanya terdiri dari dua tipe yaitu siklus hidup aseksual (konidia) dan siklus resting spores (Pell et al. 2001; Keller \& Wegensteiner 2007). Konidia merupakan struktur yang berperan dalam proses infeksi. Puluhan ribu konidia dapat diproduksi dari satu tubuh inang (Pell et al. 2001). Pada kondisi yang tidak menguntungkan atau saat populasi inang rendah, cendawan dapat bertahan lama dengan membentuk stadia resting spores yang dapat bertahan di permukaan tanah. Resting spores memiliki struktur yang kuat dengan dinding sel ganda. Resting spores akan berkecambah apabila keadaan lingkungannya memungkinkan dengan tekanan udara atau kelembapan udara yang cukup lembab (Pell et al. 2001). Stadia yang tidak bertahan lama disebut konidia. Konidia diproduksi di atas tubuh inang yang terinfeksi dan dapat disebarkan melauli angin (Hajek 2004). Kutu putih yang terinfeksi cendawan Entomophthorales di lapangan menunjukan gejala perubahan warna tubuh kutu putih menjadi kehitaman atau kelabu. Namun demikian, pemeriksaan gejala di bawah mikroskop sangat diperlukan untuk menghindari kesalahan dalam menentukan patogen penyebab penyakit. Seringkali warna kehitaman atau kelabu merupakan miselium dari cendawan saprofit yang hidupnya berasosiasi dengan $N$. fumosa .

Steinkraus et al. (1995) mengklasifikasikan serangga yang terinfeksi cendawan Entomo78 phtorales ke dalam enam kategori stadia, yaitu, serangga sehat, serangga ierinfeksi secondary conidia (konidia sekunder), hyphal bodies (badan hifa), primary conidia dan konidiofor, resting spores (spora istirahat), dan serangga terinfeksi saprophytic fungi (cendawan saprofit).

Cendawan Entomophthorales sangat berpotensi sebagai musuh alami beberapa serangga hama karena cendawan ini memiliki kemampuan epizootik (Hajek 2004). Epizootik merupakan keadaan disaat terjadi kejadian penyakit yang meluas dan menginfeksi hampir disemua tingkat pada suatu populasi serangga hama dalam waktu yang cukup singkat. Kemampuan epizootik cendawan Entomophthorales ditentukan oleh beberapa faktor, diantaranya yaitu, penyebaran patogen, populasi patogen dan populasi serangga inang (Tanada \& Kaya 1993).

Salah satu contoh cendawan Entomophthorales yang memiliki kemampuan epizootik terhadap tungau dan kutu daun adalah yang berasal dari famili Neozygitaceae. Cendawan genus Neozygites diketahui dapat menginfeksi serangga-serangga kecil dari ordo Hemiptera dan Thysanoptera serta beberapa spesies tungau dan Colembola. Pada tahun 1994 diketahui bahwa $N$. fumosa menginfeksi $P$. hereni pada tanaman ubi kayu di Brazil, dengan tigkat infeksi mencapai 9,3-64,6\% (Delalibera et.al 1997). Berdasarkan ciri-ciri yang diketahui, cendawan yang menginfeksi kutu putih P. marginatus adalah $N$. fumosa. Hal ini sesuai juga dengan yang dikemukakan oleh Keller (2007), bahwa $N$. fumosa merupakan patogen pada beberapa kutu putih dari famili Pseudococcidae.

Cendawan Entomopthorales genus Neozygites memiliki ciri-ciri konidia berbentuk globose atau filiform yang diperpanjang dengan papila diujungnya. Dengan hyphal bodies berbentuk bola atau berbentuk tidak rata, secondary konidia berbentuk menyerupai biji almond, sedangkan primary conidia berbentuk seperti bulat telur dan memiliki papila serta capilli-conidia dapat terbentuk secara pasif dari kapiler konidiofor (Humber \& Steinkraus 1998).

Infeksi cendawan Entomophtorales dipengaruhi beberapa faktor, diantaranya adalah populasi serangga hama yang menjadi inang cendawan Entomophthorales, kondisi fisik lingkungan seperti kelembaban dan suhu. Beberapa spesies 
cendawan Enthomophtorales dapat berkembang karena adanya tekanan hidrostatik dari lingkungan (Pell et al. 2001). Stadia konidia primer yang memencar akan membentuk tabung kapiler dan akan membentuk konidia sekunder yang kemudian akan menginfeksi inang. Pell et al. (2001) juga mengemukakan bahwa konidia primer yang dimiliki genus Neozygites tidak aktif menginfeksi tetapi selalu memproduksi konidia sekunder yang memiliki bentuk yang berbeda dengan konidia primer serta memiliki kemampuan untuk menginfeksi inang. Stadia hyphal bodies yang teridentifikasi memiliki bentuk bulat kecil atau seperti bola, berjumlah ribuan yang mengisi seluruh bagian tubuh kutu putih. Menurut Keller (1987), hyphal bodies merupakan struktur perkembangan vegetatif yang dimiliki oleh cendawan Entomophthorales. Stadia ini berkembang di dalam protoplas tubuh serangga. Hyphal bodies memiliki bentuk yang spesifik yang dapat dijadikan salah satu ciri penting dalam penggolongan cendawan.

Cendawan famili Neozygitaceae memiliki kemampuan berkembang dengan pesat dan mampu menghasilkan konidia dalam jumlah yang sangat banyak per individu inang walaupun inangnya berukuran kecil. Hal ini membuktikan bahwa cendawan ini efektif dalam menyebabkan keadaan epizootic. Cendawan famili Neozygitaceae mampu menghasilkan 3000 konidia primer per individu inang dalam waktu 3-4 hari siap menginfeksi inang. Cendawan ini hanya memerlukan waktu 3 hari untuk menginfeksi inangnya kemudian bersporulasi. Selain kemampuan berkembang yang pesat dan dapat menghasilkan konidia dalam jumlah yang sangat banyak, cendawan dari famili Neozygitaceae juga mampu menginfeksi hampir semua fase serangga inang kecuali telur. Hal ini berbeda dengan cendawan dari ordo Entomophthorales lainnya yang umumnya hanya menginfeksi inang pada stadia imago (Pell et al. 2001). Sebagai cendawan obligat, patogen akan memanfaatkan semaksimal mungkin sumberdaya yang ada pada serangga inang sampai serangga mati. Setelah serangga mati cendawan akan bersporulasi kemudian menginfeksi serangga sehat lainnya.

\section{KESIMPULAN}

Kutu putih pada pertanaman pepaya dan ubi kayu di Rancabungur dan Bubulak merupakan $P$. marginatus. Kelimpahan populasi P. marginarus cukup fluktuatif, namun secara umum meningkat pada minggu-minggu terakhir pengamatan.

Kelimpahan populasi di Rancabungur umumnya lebih rendah dibandingkan dengan di Bubulak. Serangga yang terinfeksi cendawan Entomophthorales mengalami perubahan warna menjadi kehitaman atau kelabu. Cendawan yang menginfeksi kutu putih di Rancabungur dan Bubulak adalah $N$. fumosa. Stadia cendawan yang ditemukan adalah stadia primary conidia, secondary conidia, hyphal bodies. Selain itu, cendawan saprofit yang berasosiasi dengan N. fumosa juga ditemukan pada kadaver kutu putih pepaya. Tingkat infeksi $N$. fumosa pada $P$. marginatus di dua lokasi dan dua tanaman tidak berbeda nyata, namun dapat diketahui bahwa cendawan tersebut berpotensi menginfeksi kutu putih pepaya.

\section{DAFTAR PUSTAKA}

Amarasekare KG, Mannion KM, Osborne LS, Epsky ND. 2008. Life history of Paracoccus marginatus (Hemiptera: Pseudococcidae) on four host plant species under laboratory conditions. Environmental Entomology 37:630-635. http:// dx.doi.org/10.1603/0046-225X(2008)37[630:LH OPMH]2.0.CO;2.

Calatayud PA, Le Rü B. 2006. Cassava-Mealybug Interactions. Paris: IRD Éditions Institut De Recherche Pour Le Développement.

Delalibera Jr, Humber R, Bento JMS, De Matos AP. 1997. First record of the entomopathogenic fungus Neozygites fumosa on the cassava mealybug Phenacoccus herreni. Journal of Invertebrate Pathology 69:276-278. http://dx.doi.org/10.1006/ jipa.1996.4638.

Hajek AE. 2004. Natural Enemies An Introduction to Biological Control. New York: Cambridge University Press. http://dx.doi.org/10.1017/ CBO9780511811838.

Humber R, Steinkraus DC. 1998. Entomopathogenic Fungal Identification. Los Angles: American Phytopathological Society and Entomological Society of America. 
Ivakdalam LM. 2010. Dampak ekonomi serangan hama asing invansif Paracoccus marginatus (Hemimptera:Pseudococcidae) pada usahatani papaya di kabupaten Bogor. M.Si. Thesis. Bogor: Institut Pertanian Bogor.

Keller S. 1987. Observations on the overwintering of Entomophthora planchoniana. Journal of Invertebrate Pathology 50:333-335. http://dx.doi. org/10.1016/0022-2011(87)90103-0.

Keller S. 2007. Anthropod-patogenic Entomphthorales: Biology, Ecology, Indentification. Luxembourg: COST Action 842.

Keller S, Wegensteiner R. 2007. Introduction. In: Keller S (Ed.), Anthropod-patogenic Entomphthorales: Biology, Ecology, Indentification. pp. 1-6. Brussels: COST Office.

Maharani Y. 2011. Biologi perkembangan dan neraca hayati kutu putih pepaya, Paracoccus marginatus (Williams \& Granara de Willink) (Hemiptera: Pseudococcidae) pada tiga jenis tumbuhan inang. M.Si. Thesis. Bogor: Institut Pertanian Bogor.

Muniappan R, Shepard BM, Watson GW, Carner GR, Sartiami D, Rauf A, and Hammig MD. 2008. First report of the papaya mealybug, Paracoccus marginatus (Hemiptera: Pseudococcidae), in Indonesia and India. Journal of Agricultural and Urban Entomology 25:37-40. http://dx.doi. org/10.3954/1523-5475-25.1.37.

Pell JK, Eilenberg J, Hajek AE, Steinkraus DC. 2001. Biology, ecology and pest management potential of Entomophthorales. In: Butt TM, C Jackson CW, Magan N (Eds.), Fungi as Biocontrol Agents: Progress, Problems and Potential. pp. 71-153. Wallingford: CABI Publishing.
Sartiami D, Dadang, Anwar R, Harahap IS. 2009. Pesebaran hama baru Paracoccus marginatus di provinsi Jawa Barat, Banten, dan DKI Jakarta. In: Nawangsih AA, Dadang, Prijono D, Nurhayati E, Harahap IS, Winasa IW, Mutaqin KH, Pudjianto, Anwar R, Hidayat SH, Supramana,. Wiyono S, Santoso S, Priyambodo S, Santoso T, Satari US, Widodo (Eds.), Strategi Perlindungan Tanaman Dalam Menghadapi Iklim Global dan Sistem Perdagangan Bebas. Prosiding Seminar Nasional Perlindungan Tanaman (Bogor, 5-6 Agustus 2009). pp. 453-462. Bogor: Pusat Kajian Pengendalian Hama Terpadu, Departemen Proteksi Tanaman, Fakultas Pertanian, IPB.

Steyenoff JL. 2001. Plant washing as a pest management technique for control of aphid (Homoptera: Aphididae). Journal of Economic Entomology 94:1492-1499. http://dx.doi. org/10.1603/0022-0493-94.6.1492.

Shylena Y. 2010. Potensi cendawan entomophthorales dalam mengendalikan kutu putih pepaya Paracoccus marginatus Williams \& Granara de Willink (Hemiptera: Pseudococcidae) di lapanganan. Skripsi. Bogor: Institut Pertanian Bogor.

Steinkraus DC, Geden JG, Rutz DA. 1995. Prevalence of Entomophthora muscae (Cohn) Fresenius (Zygomycetes: Entomophthoraceae) in house flies (Diptera: Muscidae) on diary farms in New York and induction of epizootics. Biological Control 3:93-100. http://dx.doi.org/10.1006/ bcon.1993.1015.

Tanada Y, Kaya HK. 1993. Insect Pathology. New York: Academic Press, Inc. 